\title{
Identification of aluminum resistant Andean common bean (Phaseolus vulgaris L.) genotypes.
}

\author{
Matthew W. Blair*, Hernán D. López-Marín and Idupulapati M. Rao \\ * MW Blair, H.D. López-Marín, I.M. Rao, Centro Internacional de Agricultura Tropical (CIAT), A.A. 6713, Cali, Colombia. \\ *Corresponding author: m.blair@cgiar.org \\ Received: 21 September 2009; Accepted: 24 February 2010
}

\begin{abstract}
Abbreviations: Al, aluminum; ARD, average root diameter; CIAT, Centro Internacional de Agricultura Tropical; QTL, quantitative trait loci; RB, root biomass; RER, root elongation rate; TRL, total root length; SRL, specific root length.
\end{abstract}

\section{ABSTRACT}

Aluminum (Al) toxicity is the principal abiotic constraint in acid soils of the tropics. Common bean, meanwhile, is for the most part very sensitive to this stress although certain genotypes within the species show some level of resistance, justifying screening of germplasm from both the Andean and Mesoamerican genepools to identify better performing sources. The objective of this study was to evaluate 36 genotypes of common bean under hydroponic conditions to identify root morphological traits that could be associated with Al resistance. A total of five root traits (elongation rate of the primary root, total root length, root biomass, average root diameter and specific root length) were measured using a simple nutrient solution with or without $\mathrm{Al}(20 \mu \mathrm{M})$ over a 48 hour growth period with the experiments conducted in five replicates. We found that genotypes from the Andean gene pool were more resistant to Al than Mesoamerican genotypes under these conditions, based on a smaller decrease in the elongation rate of the primary root, total root length, specific root length and a lesser increase in root diameter in the presence of Al in nutrient solution. These root traits but not root biomass can serve as selection criteria to distinguish between Al-resistant and Al-sensitive genotypes.

Key words: Abiotic stress, acid soils, aluminum resistance, Andean gene pool, common bean, root architecture

\section{INTRODUCTION}

Common bean (Phaseolus vulgaris L.) is an important dietary legume for more than 300 million people around the world, especially in developing countries with total production exceeding 23 million metric tons, seven million of which are produced in Latin America and Africa (Broughton et al., 2003). In addition, common bean is the second most important source of dietary protein in eastern and southern Africa, and the fourth in tropical America, where it is also the third most important source of calories after maize and cassava (Wortman et al., 1998; Rao, 2001). In both Africa and the Andean Region of Latin America, consumers prefer the large grains of Andean beans while in Central America and Brazil they mostly prefer the small grains originating from Mesoamerica (Broughton et al., 2003). Common bean in Latin America and Africa are produced mainly on small farms and often on hillsides characterized by low fertility soils, where nearly $40 \%$ of production areas are affected by soil acidity and aluminum (Al) toxicity, resulting in a 30 to $60 \%$ reduction in production (Wortman et al., 1998; Thung and Rao, 1999; Broughton et al., 2003).

The problems of acid soils and Al toxicity are widespread (Rao et al., 1993). In North America, 35\% of acid soils are formed by Podzols/Spodosols, whereas, in South America, Ultisols and Oxisols contribute 57\% (von-Uexküll and Mutert, 1995). The use of amendments such as lime has enabled 
bean production in different regions such as the Brazilian cerrados where Al toxicity is widespread and problematic in unlimed soils and below the tillage zone. Subsoil acidity and Al toxicity limits root growth and increases the risk of drought under rainfed conditions. It also increases the accumulation of toxic ions and decreases nutrient availability (Rao, 2001).

Mechanisms of Al resistance have been studied in several species. For example, while susceptible maize plants rapidly inhibit root elongation in specific regions of the root system when exposed to Al, the roots of resistant genotypes continue to grow (Kochian, 1995; Llugany et al., 1995; Zheng and Yang, 2005). Lee and Foy (1986) identified a relationship between resistance to Al toxicity and organic acid synthesis in common beans when they observed increased concentrations of organic acids in root extracts of two bean genotypes when exposed to Al. Miyasaka et al. (1991) later demonstrated that a resistant genotype exuded eight times as much citrate as a susceptible genotype during prolonged exposure.

In physiological terms, Al can be observed in root apices, especially in the transition zone, lying 1 to $2 \mathrm{~mm}$ behind the root tip. This area, known as the elongation zone, is highly sensitive to toxicity (Ryan et al., 1993; Sivaguru and Horst, 1998; Kollmeier et al., 2000). In common bean, Al applied to this zone inhibits root growth (Rangel et al., 2007). Symptoms of Al toxicity in beans include the production of shortened roots with the presence of thickened, but fragile roots that undergo browning (Mossor-Pietraszewska, 2001). Beans differ from cereals by being quiescent when Al treatment begins and later expressing tolerance components (Cumming et al., 1992; Rangel et al., 2007). That is, beans demonstrate a type II response pattern to Al treatment (Ma et al., 2001), which is characterized by a delay of several hours before organic acids, particularly citric acid, are exuded (Mugai et al., 2000; Shen et al., 2002a, 2002b, 2004; Stass et al., 2007). Recently, Rangel et al. (2009) demonstrated that apoplastic Al induces the inhibition of root elongation and that recovery from the stress caused by this element is controlled by reducing $\mathrm{Al}$ in the apoplast, thus permitting renewed elongation and cell division.

Although Al toxicity can be managed agronomically, improving genetic resistance to its effects is a less costly complementary approach, especially for low-fertility agricultural systems (Rao, 2001). Some accessions of common beans and $P$. coccineus $L$. have demonstrated resistance to Al, but the genotypes evaluated have always been limited in number and usually drawn from the smallgrain Mesoamerican gene pool rather than from the largegrain Andean genepool. Hence, this study aims to identify Al resistance in common bean genotypes that are mostly from the Andean gene pool based on a high throughput phenotypic screening system.

\section{MATERIALS AND METHODS}

Plant materials: A total of 36 common bean genotypes representing potential parental materials being evaluated at CIAT for their resistance to abiotic stress factors and diseases, grain quality (micronutrient contents), productivity, and/or production components, and that are genetic stocks for quantitative trait locus (QTL) studies were analyzed. The 36 common bean genotypes included 11 landraces, 11 commercial varieties, and 14 improved lines. Furthermore, 25 belonged to the Andean genepool and 11 to the Mesoamerican genepool (Table 1).

Greenhouse trial: The experiment was carried out in the greenhouse at CIAT headquarters in Cali, Colombia in MarchApril 2006, under the following conditions: relative humidity at $48-96 \%$, temperatures at $19-36^{\circ} \mathrm{C}$, and a maximum photon flux density during the day of $1100 \mu \mathrm{mol} \mathrm{m} \mathrm{m}^{-2} \mathrm{~s}^{-1}$. Uniform seedlings of similar size per genotype were selected through a preliminary evaluation of the percentage and synchronization of germination. Thus, for each genotype, 20 seeds of uniform size were chosen, placed in peat (pH 5.5), ensuring that the micropyle was oriented downwards so that the radicle would emerge vertically downwards and left for three days to germinate. From this preliminary test, we determined that, for genotypes with a high percentage and/ or effective synchronization of germination, 30 seeds had to be placed in peat. In contrast, for genotypes with a low percentage of germination and/or little synchronization, 45 seeds had to be placed in peat. After the initial testing, we selected 10 seedlings per genotype with similar root lengths for a total population size of 360 individuals for the entire experiment. 
Table 1. Common bean genotypes used in the aluminum screening trial.

\begin{tabular}{|c|c|c|c|c|c|c|c|}
\hline Genotype & Other name & Commercial Class & Source & Genepool & Race & Growth Habit & Classification \\
\hline A55 & NA & Black & CIAT & Mesoamerican & M & ॥ & Advanced Line \\
\hline AFR298 & ICA Quimbaya & Red Kidney & CIAT & Andean & $N G$ & I & Commercial Variety \\
\hline AFR708 & NA & Red Mottled & CIAT & Andean & $N G$ & I & Advanced Line \\
\hline AND277 & NA & Red Mottled & CIAT & Andean & $N G$ & I & Advanced Line \\
\hline Bayo Mochica & NA & Bayo & Peru & Andean & $P$ & III & Commercial Variety \\
\hline BRB191 & NA & Red Mottled & CIAT & Andean & $N G$ & ॥ & Advanced Line \\
\hline BRB198 & NA & Red Mottled & CIAT & Andean & $N G$ & ॥ & Advanced Line \\
\hline CAL96 & K132 & Rojo moteado & CIAT & Andean & $N G$ & I & Commercial Variety \\
\hline CAL143 & Napilira & Red Mottled & CIAT & Andean & $N G$ & I & Commercial Variety \\
\hline DOR364 & Dorado & Small Red & CIAT & Mesoamerican & M & ॥ & Commercial Variety \\
\hline Fabes & NA & Large White & Spain & Andean & $P$ & IV & Commercial Variety \\
\hline G122 & Jatu Rong & Cream Mottled & India & Andean & $N G$ & I & Landrace \\
\hline G685 & Vunikingi & Small Red & Guatemala & Mesoamerican & G & IV & Landrace \\
\hline G2333 & Umubano & Small Red & Mexico & Mesoamerican & G & IV & Landrace \\
\hline G4825 & Carioca & Carioca & Brazil & Mesoamerican & M & ॥ & Commercial Variety \\
\hline G5273 & CIAS 72 & Yellow & Mexico & Andean & $N G$ & ॥ & Commercial Variety \\
\hline G5686 & Trepador & Red Mottled & Ecuador & Andean & $N G$ & I & Landrace \\
\hline G6416 & Montcalm 023 & Red Kidney & United States & Andean & $N G$ & I & Commercial Variety \\
\hline G9603 & Jalo EEP 558 & Jalo & Brazil & Andean & $N G$ & III & Commercial Variety \\
\hline G12494 & Bola 60 & Yellow & Ecuador & Andean & $N G$ & I & Landrace \\
\hline G14016 & ICA Tundama & Red Mottled & Colombia & Andean & $N G$ & ॥ & Commercial Variety \\
\hline G14519 & Hickman Pole & Brown & United States & Mesoamerican & M & IV & Landrace \\
\hline G17716 & Bayo Florida & Bayo & Peru & Andean & $N G$ & III & Commercial Variety \\
\hline G19833 & Chaucha Chuga & Liborino & Peru & Andean & $P$ & III & Landrace \\
\hline G19862 & Velasco Largo & Pink & Peru & Andean & $N G$ & IV & Commercial Variety \\
\hline G21078 & NA & Cream & Argentina & Andean & $P$ & IV & Landrace \\
\hline G21242 & NA & Cream Mottled & Colombia & Andean & $P$ & IV & Landrace \\
\hline G23823E & NA & Cream Mottled & Peru & Andean & $P$ & ॥ & Landrace \\
\hline G50658 & Pinto Villa & Cream & Mexico & Mesoamerican & D & ॥ & Landrace \\
\hline G51294 & BAT93 & Cream & Colombia & Mesoamerican & M & ॥ & Landrace \\
\hline IJR & Jamaica Red & Pink Mottled & Jamaica & Andean & $N G$ & ॥ & Commercial Variety \\
\hline Larán Mejorado & NA & Medium White & Peru & Andean & $P$ & ॥ & Commercial Variety \\
\hline PAN72 & NA & Small White & CIAT & Mesoamerican & M & ॥ & Advanced Line \\
\hline SEQ1027 & NA & Cream Mottled & CIAT & Andean & $N G$ & ॥ & Advanced Line \\
\hline VAX3 & NA & Small Red & CIAT & Mesoamerican & M & $\|$ & Advanced Line \\
\hline VAX6 & NA & Small Red & CIAT & Mesoamerican & $M$ & ॥ & Advanced Line \\
\hline
\end{tabular}

Abbreviations: $\mathrm{D}=$ race Durango $\mathrm{G}=$ race Guatemala, $\mathrm{NG}=$ race Nueva Granada, $\mathrm{M}=$ race Mesoamérica, $\mathrm{P}=$ race Peru. 
Upon reaching the appropriate size, the seedlings were carefully removed and gently washed with deionized water to eliminate any peat that had remained on the roots. All the seedlings were selected to have hypocotyl lengths of between 1.5 and $2.0 \mathrm{~cm}$ so that they could be placed securely into a foam wedge by the stems without damaging the roots. The seedlings were placed in randomized complete block design into trays that are able to carry 24 seedlings each and transferred to hydroponic tanks that received continuous aeration and $20 \mathrm{~L}$ of a simple nutrient solution $\left(5 \mathrm{mM} \mathrm{CaCl}_{2}\right.$, $0.5 \mathrm{mM} \mathrm{KCl}, 8 \mu \mathrm{M} \mathrm{B}(\mathrm{OH})_{3}$, $\left.\mathrm{pH} 5.5\right)$ for evaluating common bean genotypes under conditions of with and without $\mathrm{Al}$ toxicity, independently of other nutritional factors, as reported by Rangel et al. (2005).

Experimental design: Eight cultivation tanks were used for the control treatment (-Al) and eight for the Al treatment $(+\mathrm{Al})$. To prevent $\mathrm{pH}$ shock, the seedlings were submitted to a period of adaptation. The $\mathrm{pH}$ in the growth solution was decreased by using $1 \mathrm{~N} \mathrm{HCl}$ as follows: for the first day a $\mathrm{pH}$ of 5.5 was established; on the second day at $8: 00 \mathrm{~h}$, pH was lowered to 5 and then at 15:00 $\mathrm{h}$ it was lowered to 4.5 . On the third day, the nutrient solution was exchanged for a fresh solution with the same $\mathrm{pH}$ for the eight control tanks. The eight Al treatment tanks also received $\mathrm{AlCl}_{3} 6 \mathrm{H}_{2} \mathrm{O}$ to a final concentration of $20 \mu \mathrm{M}$ in the $20 \mathrm{~L}$ solution as recommended for screening by Rangel et al., (2005). For each genotype, the experiments were replicated 5 times per treatment over time.

Physiological measurements and statistical analysis: Measurements included the length (in $\mathrm{mm}$ ) of the primary root at $0 \mathrm{hr}\left(\mathrm{l}_{\mathrm{i}}\right)$ and at 48 hours $\left(\mathrm{l}_{\mathrm{f}}\right)$ for each seedling of the experiment. To determine the elongation rate of the primary root (RER), the difference in length was calculated through the formula:

$$
\operatorname{RER}=\left(\mathrm{l}_{\mathrm{i}}-\mathrm{l}_{\mathrm{f}}\right) / 48 \mathrm{~h}
$$

After the treatment was over, all roots were collected, washed and scanned in TIF format, using an STD 1600 flatbed scanner (Seiko Epson Corporation, Japan) in gray scale to a resolution of 300 pixels per inch. The images were then analyzed, using WinRHIZO ${ }^{\circledR}$ 2003b software (Regent Instruments, Inc., Quebec, Canada), to determine total root length (TRL) and average root diameter (ARD). Subsequently, roots were dried in an oven at $65^{\circ} \mathrm{C}$ for $48 \mathrm{~h}$ and then weighed on an analytical scale to calculate root biomass (RB). Finally, the specific root length (SRL) was calculated as the ratio TRL/ RB. For each variable that was directly obtained, a two-way analysis of variation was carried out, using SAS software (SAS Institute, 2000). The Ryan-Einot-Gabriel-Welsch (REGW) multiple-range test was used to estimate the threshold at which the Al treatment induced a statistically significant response in the genotypes.

\section{RESULTS}

Phenotypic evaluation of Al resistance: The high throughput hydroponic system was effective at differentiating the level of Al resistance among the 36 common bean genotypes evaluated. Analyses of variance (ANOVA) revealed the degree of significance of each phenotypic characteristic evaluated in the greenhouse and whether genotype, treatment or genotype $x$ treatment effects were significant (Table 2). Significant differences were observed for the genotypes for all variables, indicating that physiological response was different in each genotype. Significant differences were also observed in the response to the treatments (+Al and $-\mathrm{Al})$ for all the variables, indicating that the presence of $\mathrm{Al}$ induced differential performance in common bean genotypes. Significant differences were also found for the genotype $\times$ treatment interaction for each of the variables, except for RB. $F$ values were highest for the interaction in the case of RER but in all cases the $F$ value of the genotype and treatment terms were higher than for the interaction indicating some stability in Al resistance. We discuss below each individual variable in turn.

Elongation rate of the primary root: For this variable, the source of variation for genotype was highly significant ( $P$ $<0.001$ ); however, the Al treatment also had an important effect on root growth. As seen in Figure 1, RER was related to the absence or presence of Al with the amount of root growth inhibition in mm per hour determined by drawing a vertical line from the genotype of interest to the discontinuous line which represented the null hypothesis $\left(\mathrm{H}_{0}\right)$ of no effect from the Al treatment. Thus, by comparing genotypes, we found that the Mesoamerican genotypes such as DOR364 and G4825 suffered a detrimental effect to their elongation rates, compared to the Andean genotypes such as CAL96 and FABES which experienced almost no inhibition. Hence, this type of analysis classified the genotypes according to their 
level of adaptation to $\mathrm{Al}$ and as a results we found that ICA Tundama, G5686, G19833 (a.k.a. Chaucha Chuga), AFR298 (a.k.a. ICA Quimbaya), SEQ1027, Bayo Mochica, and Bayo Florida, all Andean, were also resistant genotypes.

Table 2. Analyses of variance for 36 common bean genotypes evaluated under control and aluminum toxicity treatments for five root traits.

\begin{tabular}{|c|c|c|c|c|c|c|}
\hline Variable & Source & df & SS & MS & F value & $P$ value \\
\hline & Genotype & 35 & 0.0245600 & 0.00070161 & 30.61 & $<.0001$ \\
\hline \multirow[t]{3}{*}{ Root Biomass per plant (RB) } & Treatment & 1 & 0.0007143 & 0.00071432 & 31.16 & $<.0001$ \\
\hline & Gen. $x$ trt. & 35 & 0.0005648 & 0.00001614 & 0.70 & 0.8722 \\
\hline & Genotype & 35 & 0.5439671 & 0.01554192 & 29.31 & $<.0001$ \\
\hline \multirow[t]{3}{*}{ Average Root Diameter (ARD) } & Treatment & 1 & 0.2364456 & 0.23644557 & 445.97 & $<.0001$ \\
\hline & Gen. $x$ trt. & 35 & 0.0557815 & 0.00159376 & 3.01 & $<.0001$ \\
\hline & Genotype & 35 & 167900878 & 47971679 & 16.81 & $<.0001$ \\
\hline \multirow[t]{3}{*}{ Specific Root Length (SRL) } & Treatment & 1 & 952042540 & 952042540 & 333.62 & $<.0001$ \\
\hline & Gen. $x$ trt. & 35 & 319406747 & 9125907 & 3.20 & $<.0001$ \\
\hline & Genotype & 35 & 2659529.800 & 75986.566 & 29.59 & $<.0001$ \\
\hline \multirow[t]{3}{*}{ Total Root Length per plant (TRL) } & Treatment & 1 & 1203914.860 & 1203914.863 & 468.84 & $<.0001$ \\
\hline & Gen. $x$ trt. & 35 & 201642.533 & 5761.215 & 2.24 & 0.0002 \\
\hline & Genotype & 35 & 65.8229644 & 1.88065613 & 26.72 & $<.0001$ \\
\hline \multirow[t]{2}{*}{ Root Elongation Rate (RER) } & Treatment & 1 & 49.4313294 & 49.43132939 & 702.24 & $<.0001$ \\
\hline & Gen. x trt. & 35 & 12.3858293 & 0.35388084 & 5.03 & $<.0001$ \\
\hline
\end{tabular}

Gen $x$ trt. $=$ Genotype $x$ treatment interaction. Levels of $\mathrm{P}<0.01$ and $\mathrm{P}<0.001$ were significant and highly significant, respectively.

Furthermore, the results on RER under the treatments with or without Al (Figure 1) allowed us to classify the genotypes according to differential response to Al, plant vigor, genepool source, and growth habits. We determined those genotypes that responded in a statistically significant way to the Al treatment based on the significant genotype $x$ treatment effect. A multiple-range test was used to determine the threshold at which the treatment and control solutions induced statistically different responses. Hence, a first classification separated the genotypes according to their response to treatment, described in terms of whether they fell below or above the significance threshold (solid line, Figure 1). With this analysis, genotypes Bayo Mochica, SEQ1027, and ICA Quimbaya had higher elongation rates and did not show significant differences between the solutions. In contrast, genotypes CAL143, G21078 and Pinto Villa (Mesoamerican with Andean introgression) had high elongation rates but $\mathrm{Al}$ induced a significant response from them.
Conversely, genotypes DOR364, VAX3, VAX6, and BAT93 (all Mesoamerican) presented the lowest elongation rates for the two solutions, although Al did induce a statistically significant response. In contrast, genotypes BRB198 and G23823E (Andean), also presenting low elongation rates for both solutions, but did not respond statistically to the presence of Al. The second classification may distinguish genotypes according to their performance in the two nutritive solutions where the vigorous genotypes are those that have a greater possibility of generating a larger root exploration surface that also provided a greater area for absorbing water and minerals. The third classification could be described from top to bottom within Figure 1, the elliptical ovals represented a) vigorous genotypes from both genepools (mostly of type II, III or IV growth habit) with high rates of elongation; b) Andean genotypes with moderate vigor (type I or II growth habit) and intermediate rates of elongation; c) Andean or Mesoamerican genotypes with low rates of elongation; and d) Mesoamerican genotypes with low rates of elongation especially under Al. 


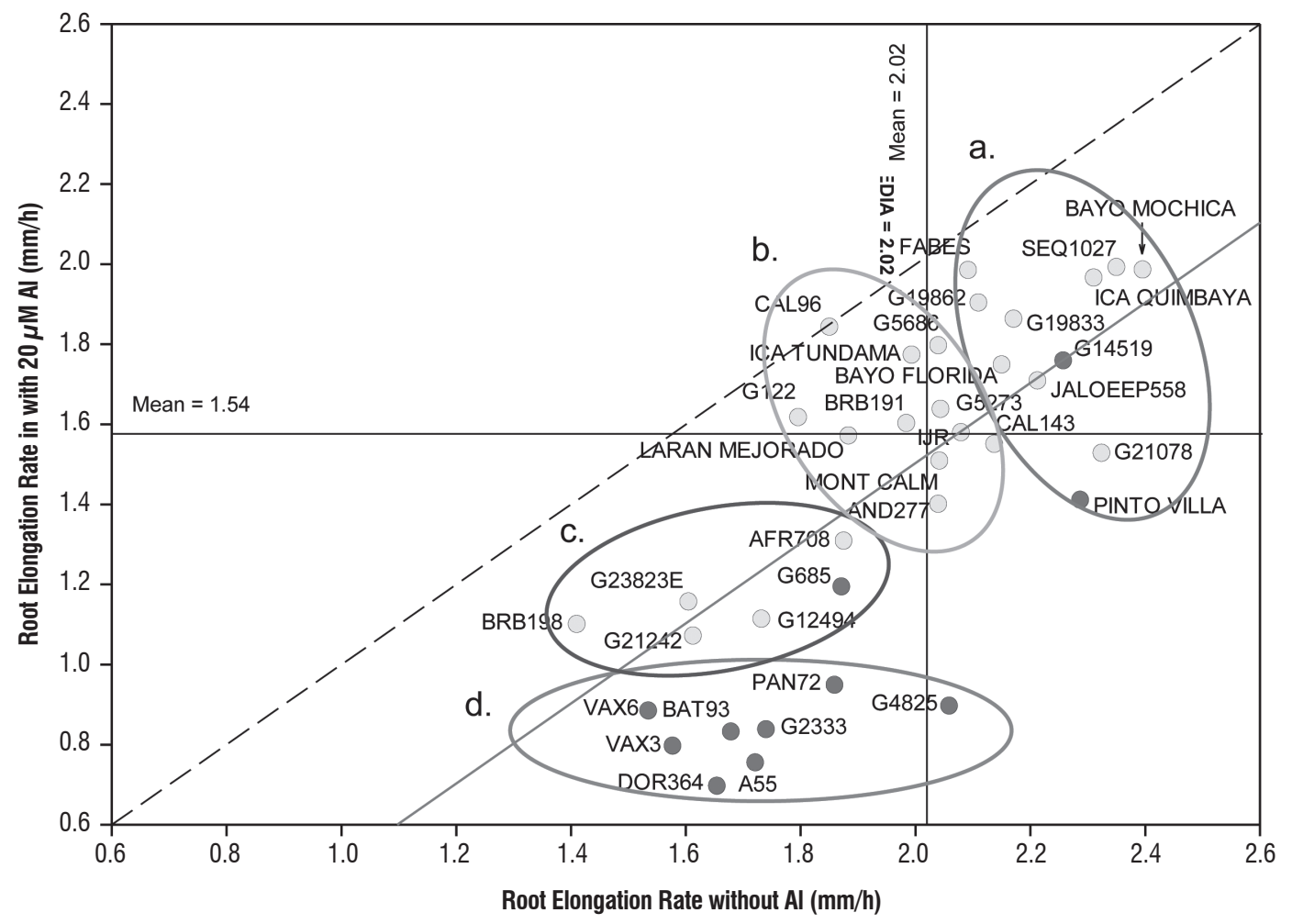

Figure 1. Relationship between elongation rate of the primary root (in $\mathrm{mm} / \mathrm{hr}$ ) under control treatment (x-axis, -Al) versus $20 \mu \mathrm{M}$ Al treatment (y-axis, $+\mathrm{Al}$ ) for 36 common bean genotypes. Light and dark circles represent Andean and Mesoamerican genotypes, respectively. Ovals from top to bottom are explained in the text and the oblique discontinuous line represents no affect of Al while the oblique continuous line represents the threshold of significance for inhibition by Al based on the REGW multiple range test. Means are given above horizontal and vertical lines within the graph that represent their values.

Total root length: Figure $2 a$ shows the effect of Al treatment on the TRL of each genotype. Inhibition of root elongation is determined by the distance from the discontinuous line, showing how many centimeters of reduced elongation occur in the whole root system. Vigorous and nonvigorous genotypes for TRL can therefore be differentiated. As for RER, which measured elongation in the primary root, Andean genotypes (light circles) such as G23823E, IJR and AND277 were observed to present higher TRL values than the Mesoamerican genotypes (dark circles) such as BAT93, VAX6, and G2333 which had the shortest root lengths in both nutrient solutions (with or without Al). This result showed, yet again, differences between the two primary gene pools, and confirmed the Andean genotypes' better adaptation to Al stress, compared with the Mesoamerican genotypes. Multiple range test showed that the threshold (solid line) at which there was a differential response between the $+\mathrm{Al}$ and $-\mathrm{Al}$ treatments.
Average root diameter: The Al treatment was found to induce roots to swell causing an increase in ARD values (Figure $2 b)$. Such swelling is a typical symptom of susceptibility and occurred principally in the Mesoamerican genotypes such as DOR364, G14519, and VAX6. Hence, susceptible genotypes appeared above the line representing the threshold for significance of treatment, as estimated by the REGW multiplerange test. In contrast, most Andean genotypes did not show significance for this physiological response of root swelling. This trait showed differences between the two primary gene pools as was observed for the previous trait. The highly resistant Andean genotype FABES had very thick roots in the control solution, nevertheless showed root swelling in the Al treatment. This finding gave rise to the questions of (1) whether this genotype is partly Mesoamerican, and (2) if this response is always required for Al resistance. The genotype with the most stability was determined to be AFR708 while the roots of G14519 swelled most significantly in response to Al. 
Root biomass: Unlike elongation rates and total root lengths which were significantly reduced by Al, there was only a slight reduction of root biomass with the Al treatment compared to control (Figure 2c). This trend may be a result of correlation with increased root diameters. Moreover, although the genotypes were distinct and Al induced different and statistically significant responses, the genotypes were not observed to respond differentially to the treatments. Hence, this trait is not informative for measuring levels of Al resistance, as it does not differentiate resistant genotypes from susceptible ones. However, Andean genotypes were observed to have larger root biomass in general compared to Mesoamerican genotypes. This provides evidence of differences in root vigor, which correlate with the two gene pools.

Specific root length: Specific root length (SRL) refers to the efficiency in the production of fine roots. It is measured in terms of the ratio between total root length and root biomass and
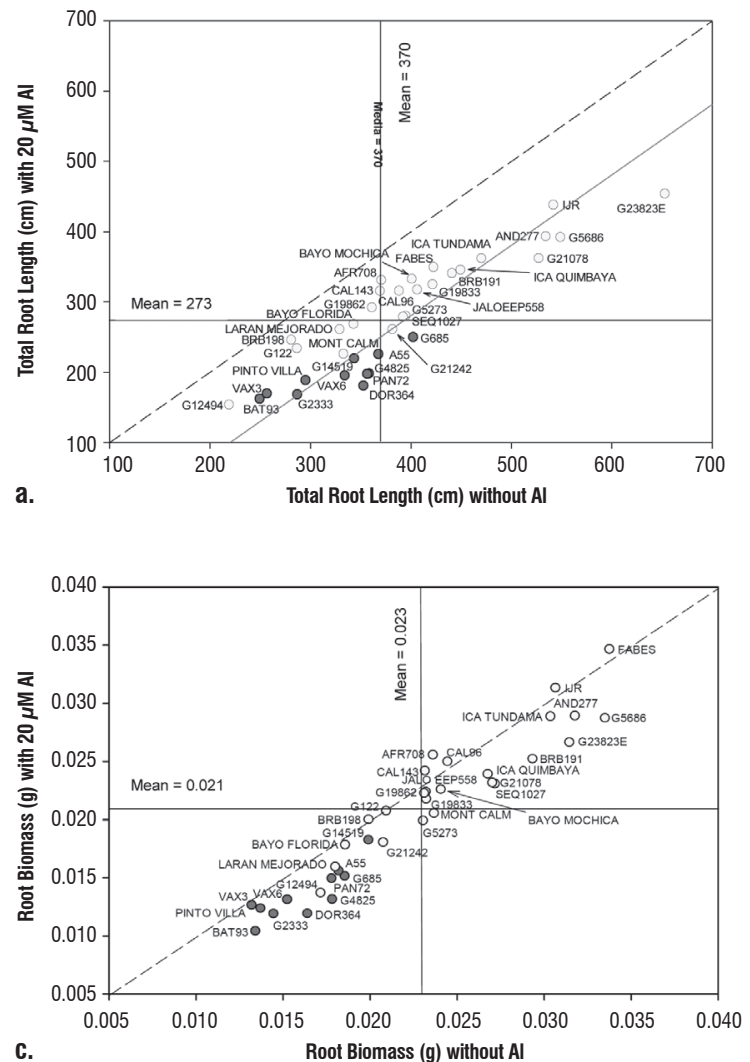

indicates the length of roots produced per unit biomass of roots. Again, highly significant differences were observed among the genotypes, treatments, and genotype $\times$ treatment interactions $(P<0.001)$. Although Mesoamerican genotypes were the most efficient in producing fine roots (greater root length per gram of root biomass), they showed a statistically different response in the Al treatment, falling below the threshold where treatment induced a statistically different response according to the REGW multiple-range test (Figure 2d). In contrast, although Andean genotypes were less efficient in producing fine roots, except for G23823E, they were less affected by Al, a characteristic that was markedly different between the two gene pools. This opens up the possibility of combining traits of interest in crosses among genotypes from different gene pools to generate progenies showing transgressive segregation with highly efficient root production and Al resistance, that can be advantageous for cultivar development.
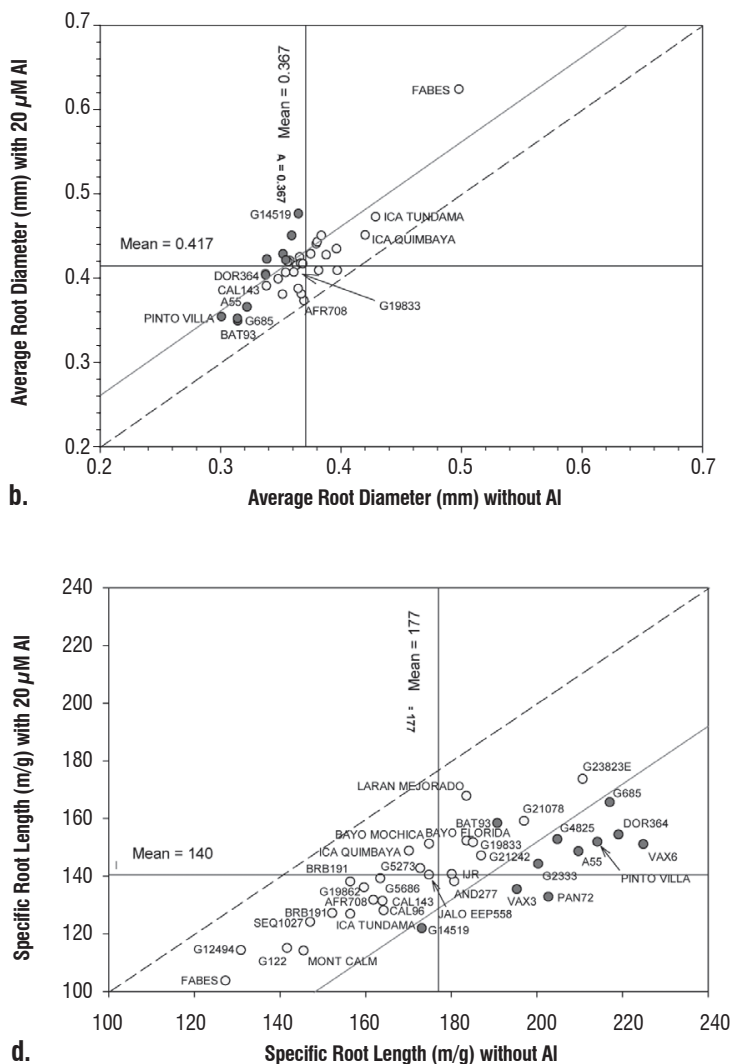

Figure 2. Response of 36 common bean genotypes under control treatment (x-axis, -Al) versus $20 \mu \mathrm{M}$ Al treatment (y-axis; +Al) for a) total root length (in cm); b) average root diameter (in $\mathrm{mm}$ ); c) root biomass (in g) and d) specific root length (in $\mathrm{m} / \mathrm{g}$ ). Light and dark circles represent Andean and Mesoamerican genotypes, respectively. Oblique discontinuous lines represent no affect of Al while the oblique continuous lines represent the threshold of significance for inhibition by Al based on the REGW multiple range test. Means are given above horizontal and vertical lines within the graph that represent their values. 
Simple correlations for relative variables: Correlations between relative variables were found to be highly significant as shown in Table 3. Correlations between the relative elongation rate of the primary root, total root length, and specific root length were directly proportional and highly significant. At the same time, they were highly but negatively correlated with average root diameter. This shows that allometric compensations are made among components of root morphology.

Table 3. Pearson simple correlations (r-values) between root traits measured on 36 common bean genotypes evaluated under control and aluminum toxicity treatments.

\begin{tabular}{|c|c|c|c|c|}
\hline Variable & RER & TRL & ARD & RB \\
\hline Root Elongation Rate (RER) & -- & & & \\
\hline Total root length per plant (TRL) & $0.776^{\star \star \star}$ & -- & & \\
\hline Average root diameter (ARD) & $-0.476^{\star \star}$ & $-0.696^{\star \star \star}$ & -- & \\
\hline Root biomass per plant (RB) & $0.612^{\star \star \star}$ & $0.837^{\star \star \star}$ & $-0.343^{*}$ & -- \\
\hline Specific root length (SRL) & $0.646^{\star * \star}$ & $0.684^{\star \star \star}$ & $-0.802^{\star \star \star}$ & $0.195 \mathrm{~ns}$ \\
\hline
\end{tabular}

Significance levels: $\left({ }^{*}\right)=P<0.05,\left({ }^{* *}\right)=P<0 .\left({ }^{* * *}\right)=P<0.001 ;$ ns $=$ not significant.

\section{DISCUSSION}

The grouping of genotypes in their reaction to Al stress corresponded largely to their classification by gene pool. In particular, within the Andean gene pool, we observed the existence of important sources of Al resistance, more evident in genotypes with type III and IV growth habits, but also in Andean genotypes of type I and II growth habits. In contrast, genotypes from the Mesoamerican gene pool were mostly sensitive to Al stress in the hydroponic system. These findings demonstrate existing genetic variability for response to $\mathrm{Al}$ toxicity in beans and, thus, the potential for plant breeders to select the most resistant genotypes.

Secondly, we found that genotypes varied in root biomass, length, average diameter and elongation rate of primary roots. These results are important because presumably genotypes that grew vigorously in the two solutions or have larger root systems, would have a greater ability to grow in acid soils with high Al saturation if field conditions are correlated with those we used in these experiments. Large root systems are known to have a greater capacity for absorbing water and minerals, as they are able to explore a larger rhizosphere (Lynch, 1995; Osmont et al., 2007). In contrast, genotypes with low vigor in the two solutions would be less able to explore the soil, possess a consequently smaller area for absorbing water and minerals, a smaller capacity for growth, and increased sensitivity to Al in soil solution. Although, in nutrient solutions these absorption areas do not present an absolute limitation, they do indeed play a fundamental role in soils (Marschner, 1995).

The Al resistance observed in this study could be due to various mechanisms which could be studied in more detail in the future. For example, variability for resistance to Al toxicity between common bean genotypes may partly be related to differences in the extension of the root elongation zone. Results from Rangel et al. (2007) showed that a resistant genotype such as ICA Quimbaya presents a larger elongation zone than does a susceptible genotype such as VAX1. This suggests that the dynamics of perceiving and responding to Al stress varies spatially (Cumming et al., 1992). Furthermore, although observations on the effect of Al were made for seedlings in our study, the plant response to Al is also known to be dependent on timing of stress. For example, for genotypes ICA Quimbaya and VAX 1 the resistant and sensitive genotypes mentioned above, elongation patterns of the primary root during the first $4 \mathrm{~h}$ of Al treatment are the same. But, after this time, the two genotypes begin developing different elongation rates, depending on the genotype's level of resistance (Rangel et al., 2007) with clearly observable differences at $48 \mathrm{~h}$ as shown previously and in this study.

According to Rangel et al. (2007), the accumulation of Al in root tips may be another feature of common bean response to Al toxicity. However, the degree of inhibition was not 
proportional to accumulation but, instead, to the sensitivity of the transition zone. In addition, the susceptible area in common beans unlike in maize extends beyond the transition zone and differences are found in as little as $24 \mathrm{~h}$ (Rangel et al., 2007). This may be reflected in the elongation rates of the primary root and total root lengths as measured in our study with significant differences found for highly sensitive (e.g., VAX 1) and highly resistant (e.g., ICA Quimbaya) genotypes. Rangel et al. (2009) later demonstrated that inhibition is induced by apoplastic $\mathrm{Al}$, and recovery in the resistant cultivar ICA Quimbaya is a result of reducing Al in the apoplast, enabling elongation and cellular division to resume (Rangel et al., 2009).

Another principal mechanism that has been correlated with resistance to Al toxicity is the exudation of organic acids. Resistant genotypes have been observed to exude more citrate than the sensitive genotypes with the degree of secretion dependent on the dosage of Al and on time (Shen et al., 2002a). However, a differential response of resistance to $\mathrm{Al}$ and exudation of citrate exists among different types of roots and common bean genotypes and is related to phosphorus deficiency and genepool origin. Shen et al. (2002b) found that large-seeded Andean beans such as G19833 and G19839 produced greater amounts of citrate, tartrate and acetate than small seeded Mesoamerican genotypes such as DOR364 and G21212 under low phosphorus conditions. The genepool differences observed by these previous studies confirm our results where Andean beans outperformed Mesoamerican beans in adaptation to the Al stress condition imposed in the study. In mechanistic terms, differences in organic acid secretion have also been attributed to differences in surface areas of the primary and basal root tips, and also to the number and activity of ionic channels (Shen et al., 2004).

Meanwhile, López-Marín et al. (2009) found that the inheritance of Al resistance in the cross of DOR364 $\mathrm{x}$ G19833 in the hydroponic system was related to QTL for low phosphorus $(\mathrm{P})$ stress tolerance in the field, suggesting the utility of this screening technique for field productivity under Al toxicity and P deficiency. In the future, we plan to study organic acid exudation in a wider range of Andean genotypes to complement the study of Shen et al. (2002b) where G19833 and G19839 produced the high amounts of citrate, to determine if this is an important mechanism of Al resistance in a wide range of common bean genotypes. We also plan to test field performance in terms of seed yield under Al-toxic soil conditions, although this is complicated by the differential adaptation of Andean and Mesoamerican bean genotypes to sites with Al toxicity. Initial screening at low P sites showed the adaptation of $\mathrm{Al}$ resistant genotypes used in this study which may indicate that the release of organic acids is important for both $\mathrm{P}$ uptake and Al resistance.

In conclusion, the results of this study are promising, because they confirm that the high throughput phenotyping system enabled observations of differences in response to Al treatment among different common bean genotypes and that the Andean genepool is a source of Al resistance. The parameters evaluated are useful as they differentiated resistance to Al toxicity within the Andean and Mesoamerican gene pools. As a result, except for root biomass, the other four root parameters are useful for selecting resistant genotypes, with the RER being the most informative. The methodology implemented for selecting resistant genotypes could also be useful in programs to improve commercial beans.

Acknowledgements: The authors wish to acknowledge the financial support from BMZ/GTZ (Contract No. 05.7860.9001-00), Germany. Our thanks also go to $G$. Manrique and M.C. Duque for their advice on hydroponic methodology and statistical analysis, respectively.

\section{REFERENCES}

Broughton WJ, Hernandez G, Blair M, Beebe S, Gepts P, Venderleyden J (2003) Bean (Phaseolus spp) - model food legumes. Plant and Soil 252: $55-128$.

Cumming JR, Cumming AB, Taylor GJ (1992) Patterns of root respiration associated with the induction of aluminium tolerance in Phaseolus vulgaris. $J$ Exp. Bot. 43: 1075-1081.

Kochian LV (1995) Cellular mechanism of aluminum toxicity and resistance in plants. Annu Rev Plant Physiol Plant Mol. Biol. 46: 237-60.

Kollmeier M, Felle HH, Horst WJ (2000) Genotypical differences in aluminum resistance of maize are expressed in the distal part of the transition zone. Is reduced basipetal auxin flow involved in inhibition of root elongation by aluminum? Plant Physiol. 122: 945-956.

Lee EH, Foy CD (1986) Aluminum tolerances of two snap bean cultivars related to organic acid content evaluated by high-performance liquid chromatography. J. Plant Nutr. 9: 1481-1498.

Llugany M, Poschenrieder C, Barceló J (1995) Monitoring of aluminiuminduced inhibition of root elongation in four maize cultivars differing in tolerance to aluminium and proton toxicity. Physiol. Plant. 93: 265-271.

López-Marín HD, Rao IM, Blair MW (2009) Quantitative trait loci for aluminum resistance in common bean (Phaseolus vulgaris L.) Theor Appl Genet 119:449-458

Lynch J (1995) Root architecture and plant productivity. Plant Physiol. 109: $7-13$ 
Ma JF, Ryan PR, Delhaize E (2001) Aluminium tolerance in plants and the complexing role of organic acids. Trends Plant Sci. 6: 273-278.

Miyasaka S, Bute J, Howell R, Foy C (1991) Mechanisms of aluminum tolerance in snapbeans. Root exudation of citric acid. Plant Physiol. 96: 737-746.

Mossor-Pietraszewska T (2001) Effect of aluminium on plant growth and metabolism. Acta Biochimica Polonica 48(3): 673-686.

Mugai EN, Agong SG, Matsumoto H (2000) Aluminium tolerance mechanisms in Phaseolus vulgaris L.: Citrate synthase activity and TTC reduction are well correlated with citrate secretion. Soil Sci. Plant Nutr. 46: 939-950.

Osmont KS, Sibout R, Hardtke CS (2007) Hidden branches: Developments in root system architecture. Annu. Rev. Plant Biol. 58: 93-113.

Rangel AF, Mobin M, Rao IM, Horst WJ (2005) Proton toxicity interferes with the screening of common bean (Phaseolus vulgaris L.) genotypes for aluminium resistance in nutrient solution. J. Plant Nutr. Soil Sci. 168: 607-616.

Rangel AF, Rao IM, Horst WJ (2007) Spatial aluminium sensitivity of root apices of two common bean (Phaseolus vulgaris L.) genotypes with contrasting aluminium resistance. J. Exp. Bot. 58: 3895-3904.

Rangel AF, Rao IM, Horst WJ (2009) Intracellular distribution and binding state of aluminum in root apices of two common bean (Phaseolus vulgaris) genotypes in relation to Al toxicity. Phys Plant. 135: 162-173.

Rao IM (2001) Role of physiology in improving crop adaptation to abiotic stresses in the tropics: The case of common bean and tropical forages. Handbook of Plant and Crop Physiology. Pessarakli M., Marcel Dekker, Inc., New York, USA: 613.

Rao IM, Zeigler RS, Vera R, Sarkarung S (1993) Selection and breeding for acid-soil tolerance in crops: Upland rice and tropical forages as case studies. BioScience 43: 454-465.
Ryan PR, DiTomaso JM, Kochian LV (1993) Aluminum toxicity in roots: an investigation of spatial sensitivity and the role of the root cap. J. Exp. Bot. 44: $437-446$

SAS, S.I. 2000. SAS System. SAS/STAT User's guide version 8, pp 3884. Cary, North, Carolina, USA.

Shen H, Yan X, Cai K, Matsumoto H (2004) Differential Al resistance and citrate secretion in the tap and basal roots of common bean seedlings. Phys. Plant. 121: 595-603.

Shen, H., Yan X, Wang X, Zheng S (2002a) Exudation of citrate in common bean in response to aluminum stress. J. Plant Nutr. 25: 1921-1932.

Shen H, Yan X, Zhao M, Zheng S, Wang X (2002b) Exudation of organic acids in common bean as related to mobilization of aluminum- and iron-bound phosphates. Env. Exp. Bot. 48:1-9.

Sivaguru M, Horst WJ (1998) The distal part of the transition zone is the most aluminum-sensitive apical root zone of maize. Plant Physiol. 116: 155-163.

Stass A, Kotur Z, Horst WJ (2007) Effect of boron on the expression of aluminium toxicity in Phaseolus vulgaris. Physiol. Plant. 131: 283-290.

Thung M, Rao IM (1999) Integrated management of abiotic stresses. Common Bean Improvement in the Twenty-first Century. S. P. S. (ed). Dordrecht, The Netherlands, Kluwer Academic Publishers: 331-370.

von-Uexküll HR, Mutert E (1995) Global extent, development and economic impact of acid soils. Plant and Soil 171: 1-15.

Wortman, C.S., R.A. Kirkby., C.A. Eledu and D.J. Allen. 1998. Atlas of Common Bean (Phaseolus vulgaris L.) Production in Africa. CIAT, Cali, Colombia.

Zheng SJ, Yang JL (2005) Target sites of aluminum phytotoxicity. Biol. Plant. 49: 321-331. 